\title{
AVALIAÇÃO DA TENDÊNCIA DE INCORPORAÇÃO DE ÁGUA DO DIESEL S10 E DIESEL S500 E SUAS MISTURAS COM BIODIESEL ATRAVÉS DO MÉTODO DA DEMULSIBILIDADE
}

\author{
Laila C. Cortas ${ }^{1}$, Roberta M. Teixeira ${ }^{1}$, Sergio L.C. Viscardi ${ }^{1}$ \\ ${ }^{1}$ Ipiranga Produtos de Petróleo S.A., Rio de Janeiro, Brasil
}

E-mails: 1ailac@ipiranga.com.br, $\underline{\text { robertamt@ipiranga.com.br, viscardi@ipiranga.com.br }}$

\section{RESUMO}

A utilização de misturas de biodiesel ao diesel como combustível tem apresentado um potencial promissor no mundo inteiro, devido a sua enorme contribuição ao meio ambiente, com a redução dos níveis de poluição ambiental, assim como o emprego de uma nova fonte de energia renovável em substituição ao diesel e outros derivados do petróleo. No ano de 2014, o percentual do teor de biodiesel no óleo diesel aumentou duas vezes, de 5\% para 6\% e atualmente utiliza-se uma proporção de $7 \%$ na mistura. Um dos principais problemas relativos ao biodiesel é assegurar sua qualidade ao longo de toda a cadeia produtiva, principalmente em relação a sua alta higroscopicidade. Devido a isso, as especificações estão mais restritivas e o controle mais rigoroso das propriedades do biodiesel, principalmente o teor de água. Portanto, é de fundamental importância que se desenvolvam testes e estudos capazes de avaliar essa importante característica, tanto para o biodiesel puro, quanto para suas misturas com o diesel. Sendo assim, o objetivo do presente trabalho é avaliar a capacidade de incorporação de água da fase óleo após o ensaio de demulsibilidade de amostras de óleo diesel S10 e de óleo diesel S500 com diferentes percentuais de biodiesel, identificando diferenças nas características dessas amostras com relação a maior afinidade com a água e propriedades de formação de emulsões.

Palavras-chave: biodiesel, óleo diesel, blendas, higroscopicidade, demulsibilidade.

\section{INTRODUÇÃO}

O óleo diesel é um combustível derivado do petróleo sendo constituído basicamente por hidrocarbonetos (C9 a C28). Alguns compostos presentes no diesel, além de apresentar carbono e hidrogênio, apresentam também enxofre e nitrogênio [1]. Produzido a partir do refino do petróleo, o óleo diesel é formulado através da mistura de diversas correntes como querosene, gasóleos, nafta pesada, diesel leve, diesel pesado, etc., provenientes das diversas etapas de processamento do óleo bruto [2]. As proporções destes componentes no óleo diesel são aquelas que permitem enquadrar o produto final dentro das especificações previamente definidas e que são necessárias para permitir um bom desempenho do produto, além de minimizar o desgaste nos motores e componentes bem como dos poluentes gerados na queima do produto em níveis aceitáveis. 
O enxofre é um contaminante dos derivados de petróleo em geral (alguns petróleos contêm mais compostos de enxofre, outros menos). Seu teor nos derivados é controlado para evitar formação de produtos corrosivos na combustão e, principalmente, para reduzir os compostos poluentes (dióxido e trióxido de enxofre e material particulado) na queima do combustível [3]. Os limites cada vez menores para as emissões formadas na queima dos combustíveis exigem combustíveis com características especiais e especificações mais rigorosas.

Com o objetivo de garantir a qualidade do diesel utilizado, a Agência Nacional do Petróleo, Gás Natural e Biocombustíveis (ANP) é o órgão regulamentador de derivados de petróleo e combustíveis no Brasil e regulamenta a especificação para diversos ensaios através da Resolução ANP n 50/2013 [4], indicando normas nacionais e internacionais que devem ser seguidas como forma de padronizar as metodologias.

O biodiesel é definido segundo a ANP como um combustível composto de alquil ésteres de ácidos carboxílicos de cadeia longa, produzido a partir da transesterificação e/ou esterificação de matérias graxas, de gorduras animais de origem vegetal ou animal, e que atenda a especificação contida no Regulamento Técnico [5].

Os óleos vegetais são constituídos predominantemente por triacilglicerídeos (três ácidos graxos de cadeia longa ligados na forma de ésteres a uma molécula de glicerol) e como constituintes em menores proporções, os ácidos graxos livres, os monoglicerídeos e os diglicerídeos, além de uma pequena quantidade de outros constituintes não glicerídicos, tais como tocoferóis, carotenóides, esteróis, etc. [6,7].

Uma das vantagens de seu uso se deve ao fato de ter uma menor contribuição em relação ao diesel para a poluição atmosférica devido à baixa emissão de substâncias como: $\mathrm{CO}, \mathrm{SO}_{\mathrm{X}} \mathrm{e}$ hidrocarbonetos aromáticos $[8,9]$. Além disso, ao substituir parcialmente o óleo diesel faz com que seu consumo diminua [10].

A introdução do biodiesel na matriz energética brasileira ocorreu a partir da criação de seu marco regulatório com o Programa Nacional de Produção e Uso de Biodiesel (PNPB) criado por Decreto Lei em 23 de dezembro de 2003 e complementado pela Lei no 11.097 de 13 de janeiro de 2005.

A ANP determinou que no período de 2005 a 2007 o biodiesel fosse utilizado de forma facultativa, misturado ao óleo diesel na proporção máxima de $2 \%$ de biodiesel para $98 \%$ de diesel, formando o chamado combustível B2. Sua adição ao óleo diesel nesta proporção passou a ser obrigatória em janeiro de 2008. Contudo, a Resolução 02/2008 do Conselho Nacional de Política Energética (CNPE) tornou obrigatório o uso do combustível B3, ou seja, com a adição de 3\% de biodiesel ao diesel a partir de $1^{\circ}$ de julho de 2008 (CNPE, 2008) [11].

A partir de 2013, esta proporção aumentou para 5\% de biodiesel no diesel (B5), e acordo com a Medida Provisória n ${ }^{\circ} 647$ / 2014 [12], o teor de biodiesel no diesel passou para 6\%, a partir de $1^{\circ}$ de julho deste ano e para $7 \%$, a partir de $1^{\circ}$ de novembro, como uma alternativa para a redução de custos com a importação do diesel (ANP, 2014) [13].

Assim como é feito com o diesel, a ANP regulamenta a especificação do biodiesel através da Resolução $\mathrm{n}^{\circ}$ 45/2014 [13], a qual contempla metodologias de análises e limites determinados. 
Desta forma, existe hoje uma preocupação em controlar a qualidade do biodiesel, devido seu processo natural de degradação, corrosão ou adulteração, e consequentemente as suas misturas ao diesel $[14,7]$.

Devido a sua maior polaridade, o biodiesel tem uma maior afinidade com a água que o diesel, fazendo com que ele absorva facilmente água, o que pode provocar o crescimento microbiano e a formação de borras nos tanques, sendo necessário fazer uma drenagem e limpeza em todos os tanques de armazenagem com maior frequência. Para assim, garantir que o teor de água esteja abaixo do limite máximo estabelecido é fundamental [15].

Neste presente trabalho, foi avaliada a propriedade de demulsibilidade, que não consta na Especificação do combustível e a propriedade do teor de água da fase óleo após o ensaio de demulsibilidade e assim avaliar o quanto se absorveu de água em amostras de Diesel S10 e Diesel S500, sem biodiesel e com, 5\% de biodiesel e 10\% de biodiesel. Com o objetivo de avaliar a capacidade que possuem os combustíveis de não formarem emulsões com a água.

\section{MATERIAL E MÉTODOS}

\subsection{Combustíveis}

As amostras de óleo diesel A S10 e S500 comerciais utilizados neste trabalho são especificadas de acordo com os parâmetros listados na Resolução ANP n 50/2013 [4].

A amostra de biodiesel utilizada neste trabalho é de soja e de sebo (90:10) e é especificada de acordo com os parâmetros listados na Resolução ANP n 45/2014 [13].

Foram coletadas na Base de Distribuição da Ipiranga Produtos de Petróleo S.A. e preparadas no laboratório misturas volumétricas, conforme Tabela 1.

Tabela 1 - Misturas preparadas para os testes.

\begin{tabular}{|c|c|c|c|}
\hline \multicolumn{4}{|c|}{ Amostras de Diesel BX } \\
\hline Diesel S10 & $\begin{array}{c}\text { Sem Biodiesel } \\
\text { (B0) }\end{array}$ & $\begin{array}{c}5 \% \text { de biodiesel } \\
\text { (B5) }\end{array}$ & $\begin{array}{c}10 \% \text { de biodiesel } \\
(\mathrm{B} 10)\end{array}$ \\
\hline Diesel S500 & $\begin{array}{c}\text { Sem Biodiesel } \\
\text { (B0) }\end{array}$ & $\begin{array}{c}5 \% \text { de biodiesel } \\
\text { (B5) }\end{array}$ & $\begin{array}{c}10 \% \text { de biodiesel } \\
\text { (B10) }\end{array}$ \\
\hline
\end{tabular}

As amostras preparadas para os testes foram analisadas para verificação de suas conformidades segundo a ANP (ANP n 45/2014 e ANP n 50/2013) [13,4].

As características físico-químicas avaliadas para o biodiesel (B100), o diesel A S10, o diesel A S500 e as misturas foram: Aspecto [16], Massa Específica à $20{ }^{\circ} \mathrm{C}$ (densímetro automático DMA 4500) [17], Viscosidade Cinemática à $40{ }^{\circ} \mathrm{C}$ (viscosímetro automático Cannon CAV 2200) [18], Teor de Enxofre (ANTEK 9000HS) [19], Ponto de Fulgor (Flash Point Controle TANAKA APM 7) [20] e teor de água pelo método do Karl Fischer (756 KF Coulometer) [21]. 
Realizou-se o ensaio de demulsibilidade nas misturas preparadas, avaliando-se a interface e formação de emulsão. E em seguida, retirou-se uma alíquota da fase óleo para quantificar a água absorvida nesta.

\subsection{Ensaio de Demulsibilidade}

De acordo com a ABNT NBR 14172 [22] (ou ASTM D1401) [23], este ensaio avalia a capacidade que os óleos derivados de petróleo possuem de se separar da água e a avalia a presença de emulsões e a estabilidade destas.

Uma mistura composta por $40 \mathrm{~mL}$ da amostra e $40 \mathrm{~mL}$ de água destilada é agitada por 5 minutos a $(54+1){ }^{\circ} \mathrm{C}$ em uma proveta graduada. $\mathrm{O}$ tempo necessário para a separação da emulsão assim formada é anotado. Se houver separação completa após 40 minutos, são anotados os volumes das fases: óleo, água e emulsão, remanescentes neste tempo.

Este ensaio não está contemplado na especificação (ANP $n^{\circ}$ 50/2014) [4] que regulamenta as características da qualidade do óleo diesel. Porém, a partir desta análise consegue-se verificar o tempo necessário para separação da água livre e formação de emulsões nos óleos bem como a capacidade de incorporação de água nestes combustíveis.

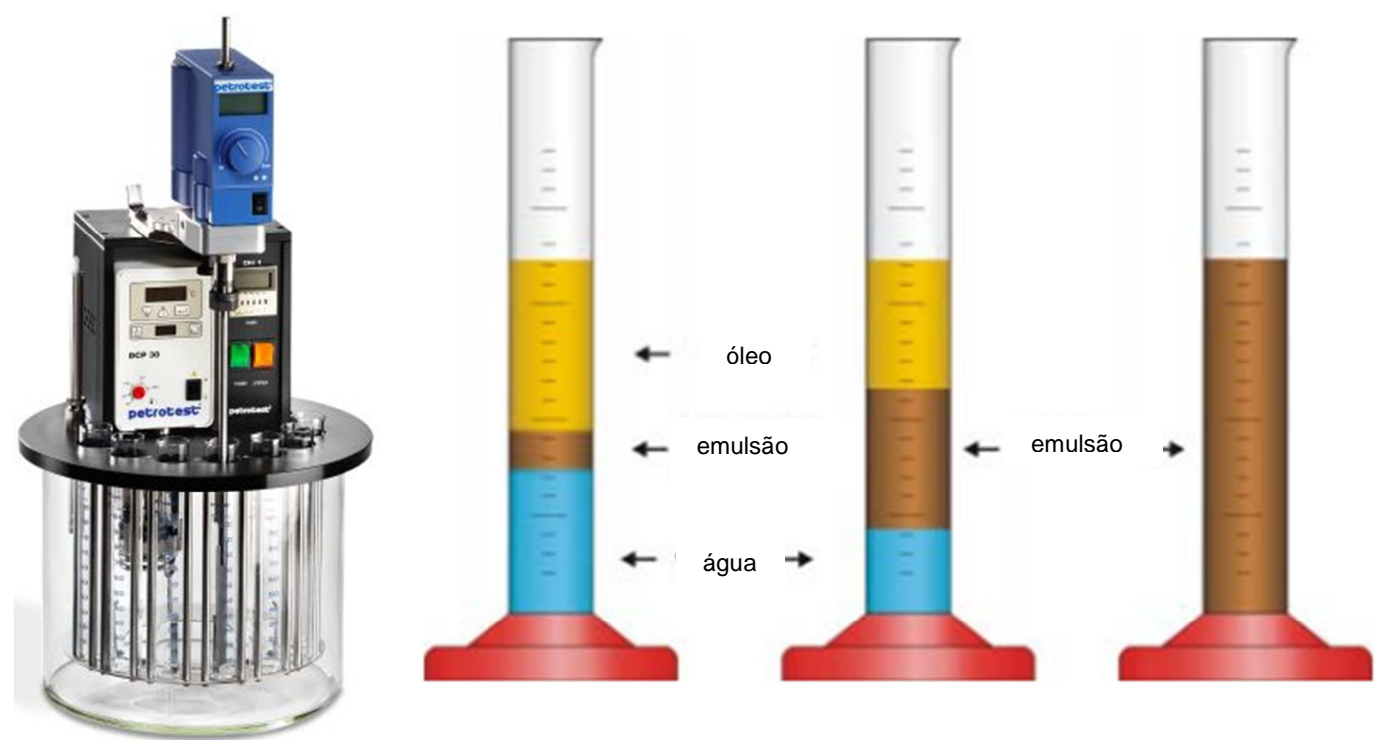

Figura 1 - Equipamento utilizado para o ensaio de demulsibilidade e representação após o ensaio de amostras e suas fases (óleo/água/emulsão).

Após o teste de demulsibilidade, foi realizada a avaliação da turbidez das amostras, de acordo com um teste padronizado na ASTM, que avalia o grau de turbidez de um óleo, de acordo com a escala Haze (ASTM D4176) [24].

\subsection{Teor de água pelo método do Karl Fischer}

De acordo com a ASTM D6304 [21], a determinação da umidade em amostras de derivados de petróleo e biodiesel através da análise coulométrica por Karl Fischer. Por meio de titulação coulométrica a água presente em uma amostra pode ser 
determinada. Este método abrange uma larga faixa de concentração $(\mathrm{mg} / \mathrm{kg})$ de água e fornece resultados precisos e confiáveis. Determinar a quantidade de água presente em uma amostra é importante, pois ela pode se dispersar e emulsionar no óleo e, dependendo da densidade do mesmo pode ocorrer separação de fases.

Este método está contemplado na Especificação do Biodiesel (ANP n 45/2014) [13] e o limite máximo permitido é de $200 \mathrm{mg} / \mathrm{kg}$ de água nas amostras.

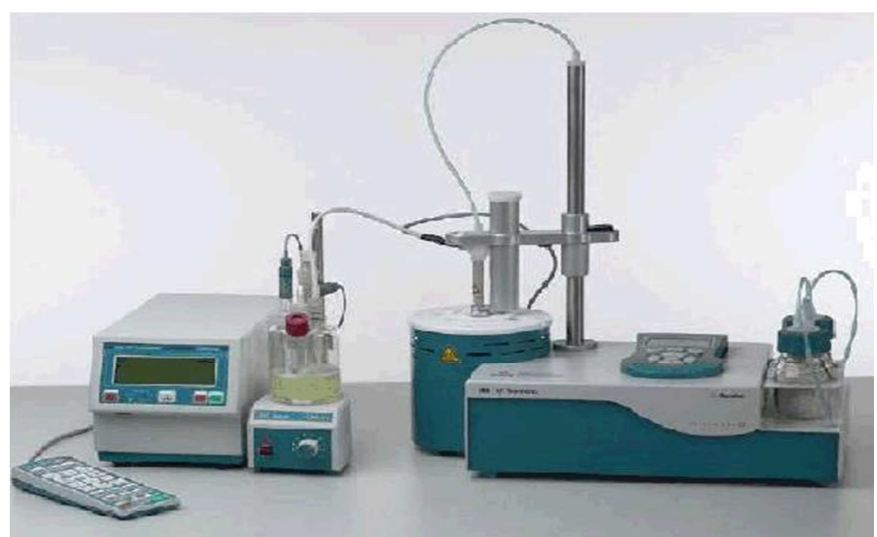

Figura 2 - Equipamento para quantificação de água - Karl Fischer.

\section{RESULTADOS E DISCUSSÃO}

Os parâmetros físico-químicos para o biodiesel puro (B100) foram determinados conforme a Resolução ANP 45/2014 [13] no sentido de avaliar sua concordância com esta especificação, sendo apresentados na Tabela 2. Os resultados obtidos nos ensaios indicam que o B100 utilizado neste trabalho encontra-se dentro dos limites permitidos pela respectiva Resolução (ANP, 2014) [13].

Tabela 2 - Caracterização do biodiesel puro (B100).

\begin{tabular}{|l|c|c|c|}
\hline \multicolumn{1}{|c|}{ Ensaios } & Método & Limite & Resultado \\
\hline Aspecto & Visual & LII* & LII* \\
\hline $\begin{array}{l}\text { Massa Específica a } 20^{\circ} \mathrm{C} \\
\left(\mathrm{kg} / \mathrm{m}^{3}\right)\end{array}$ & ASTM D4052 & 850 a 900 & 877,3 \\
\hline $\begin{array}{l}\text { Viscosidade Cinemática a } 40^{\circ} \mathrm{C} \\
\left(\mathrm{mm}^{2} / \mathrm{s}\right)\end{array}$ & ASTM D445 & 3,0 a 6,0 & 4,52 \\
\hline Ponto de Fulgor $\left({ }^{\circ} \mathrm{C}\right)$ & ASTM D93 & Mín. 100,0 & 140,0 \\
\hline Teor de Enxofre total $(\mathrm{mg} / \mathrm{kg})$ & ASTM D5453 & Máx. 10 & 1,3 \\
\hline Teor de água $(\mathrm{mg} / \mathrm{kg})$ & ASTM D6304 & Máx. 200,0 & 157,3 \\
\hline
\end{tabular}

*LII = Límpido e Isento de Impurezas

Os resultados das análises de qualidade das amostras de óleo diesel A S10 e suas misturas com biodiesel estão listados na Tabela 3, comparando-as com os limites estabelecidos na Resolução (ANP, 2013) [4]. 
Tabela 3 - Comparação das características do Diesel A S10 e de suas misturas com biodiesel.

\begin{tabular}{|l|c|c|c|c|c|}
\hline \multirow{2}{*}{ Ensaios } & \multirow{2}{*}{ Método } & \multirow{2}{*}{ Limite } & \multicolumn{3}{c|}{ Amostras Diesel S10 } \\
\cline { 4 - 6 } & & & B0 & B5 & B10 \\
\hline Aspecto & ABNT NBR 14954 & LII & LII & LII & LII \\
\hline $\begin{array}{l}\text { Massa Específica a } \\
20^{\circ} \mathrm{C}\left(\mathrm{kg} / \mathrm{m}^{3}\right)\end{array}$ & ASTM D4052 & $\begin{array}{c}815,0 \text { a } \\
850,0\end{array}$ & 827,6 & 832,5 & 840,1 \\
\hline $\begin{array}{l}\text { Viscosidade } \\
\text { Cinemática a } 40^{\circ} \mathrm{C} \\
\left(\mathrm{mm}^{2} / \mathrm{s}\right)\end{array}$ & ASTM D445 & 2,0 a 4,5 & 3,10 & 3,14 & 3,22 \\
\hline Ponto de Fulgor $\left({ }^{\circ} \mathrm{C}\right)$ & ASTM D93 & Mín. 38,0 & 60,0 & 61,0 & 62,0 \\
\hline $\begin{array}{l}\text { Teor de Enxofre total } \\
(\mathrm{mg} / \mathrm{kg})\end{array}$ & ASTM D5453 & Máx. 10 & 3,0 & 3,0 & 3,0 \\
\hline Teor de água $(\mathrm{mg} / \mathrm{kg})$ & ASTM D6304 & Máx. 200,0 & 83,1 & 56,4 & 87,7 \\
\hline
\end{tabular}

Os resultados das análises de qualidade das amostras de óleo diesel A S10 e suas misturas com biodiesel estão listados na Tabela 3, comparando-as com os limites estabelecidos na Resolução (ANP, 2013) [4].

Tabela 4 - Comparação das características do Diesel A S500 e de suas misturas com biodiesel.

\begin{tabular}{|l|c|c|c|c|c|}
\hline \multirow{2}{*}{ Ensaios } & \multirow{2}{*}{ Método } & \multirow{2}{*}{ Limite } & \multicolumn{3}{c|}{ Amostras Diesel S500 } \\
\cline { 4 - 6 } & & & B0 & B5 & B10 \\
\hline Aspecto & ABNT NBR 14954 & LII & LII & LII & LII \\
\hline $\begin{array}{l}\text { Massa Específica a } \\
20^{\circ} \mathrm{C}\left(\mathrm{kg} / \mathrm{m}^{3}\right)\end{array}$ & ASTM D4052 & $\begin{array}{c}815,0 \text { a } \\
865,0\end{array}$ & 846,5 & 846,5 & 846,5 \\
\hline $\begin{array}{l}\text { Viscosidade } \\
\begin{array}{l}\text { Cinemática a } 40^{\circ} \mathrm{C} \\
\left(\mathrm{mm}^{2} / \mathrm{s}\right)\end{array}\end{array}$ & ASTM D445 & 2,0 a 5,0 & 2,81 & 3,15 & 3,16 \\
\hline Ponto de Fulgor $\left({ }^{\circ} \mathrm{C}\right)$ & ASTM D93 & Mín. 38,0 & 44,0 & 46,0 & 47,0 \\
\hline $\begin{array}{l}\text { Teor de Enxofre } \\
\text { total (mg/kg) }\end{array}$ & ASTM D5453 & Máx. 500 & 403 & 389 & 378 \\
\hline $\begin{array}{l}\text { Teor de água } \\
(\mathrm{mg} / \mathrm{kg})\end{array}$ & ASTM D6304 & Máx. 500,0 & 73,5 & 70,8 & 100,8 \\
\hline
\end{tabular}

Foi observado que o aumento do teor de biodiesel no óleo diesel promove uma elevação nas características físico-químicas; massa específica, viscosidade cinemática, ponto de fulgor. E estes resultados são esperados uma vez que estes métodos analíticos avaliam as propriedades inerentes às estruturas, já que o biocombustível é formado por ésteres e possui interações moleculares diferentes do óleo diesel, que tem na composição basicamente hidrocarbonetos.

Quanto à análise do teor de enxofre foi observada uma redução com o aumento da quantidade do teor de biodiesel na mistura com o óleo diesel S500, enfatizando sua eficiência ambiental, gerando menores níveis de emissão de $\mathrm{SO}_{\mathrm{X}}$ para a atmosfera. 
Os valores do teor de água de todas as misturas ficaram dentro dos limites estabelecidos pelas Resoluções (ANP, 2013 e ANP, 2014) [13, 4]. Observa-se um sutil aumento nesta propriedade, com o acréscimo de biodiesel, no Diesel S10 e no Diesel S500, devido à fácil tendência do biodiesel em absorver água.

Nos ensaios de demulsibilidade realizados com o Diesel A S10, o Diesel A S500 e suas misturas, as avaliações foram baseadas na tendência de formação de emulsões e a capacidade de incorporação de água. Os resultados obtidos após o ensaio estão na Tabela 5 e estão reportados conforme a norma ASTM D1401 [23], fase óleo (mL), fase água $(\mathrm{mL})$, emulsão formada $(\mathrm{mL})$ e o tempo necessário para separação destas fases, considerando que o máximo permitido é de 40 minutos.

Tabela 5 - Resultados dos ensaios de Demulsibilidade nas amostras de Diesel A S10, Diesel A S500 e de suas misturas com biodiesel.

\begin{tabular}{|c|c|c|c|c|c|c|c|c|c|c|c|c|}
\hline & \multicolumn{4}{|c|}{ B0 } & \multicolumn{5}{c|}{ B5 } & \multicolumn{3}{c|}{ B10 } \\
\cline { 2 - 15 } & Amostras & A & E & T & O & A & E & T & O & A & E & T \\
\hline $\begin{array}{c}\text { Diesel } \\
\text { S10 }\end{array}$ & 40 & 40 & 0 & $0 *$ & 40 & 40 & 0 & 5 & 40 & 38 & 2 & 40 \\
\hline $\begin{array}{c}\text { Diesel } \\
\text { S500 }\end{array}$ & 40 & 40 & 0 & $0 *$ & 40 & 38 & 2 & 40 & 40 & 37 & 3 & 40 \\
\hline
\end{tabular}

$\mathrm{O}=$ Óleo $(\mathrm{mL}) / \mathrm{A}=$ água $(\mathrm{mL}) / \mathrm{E}=$ emulsão $(\mathrm{mL}) / \mathrm{T}=$ tempo $(\mathrm{min})$

*Amostras separaram de imediato, logo após a agitação do ensaio.

No estudo da demulsibilidade, para as amostras de Diesel B0 S10 e Diesel B0 S500, não foi observado diferenças, nas duas amostram a separação das fases óleo/água ocorreu após a agitação e não houve a presença de emulsão. Com a adição de biodiesel no diesel, a amostra de Diesel B5 S10, apresentou o mesmo resultado, sem a formação de emulsão, porém, com um tempo de separação de fases óleo/água de 5 minutos. Ao avaliar o Diesel B5 S500, observou-se a presença de $2 \mathrm{~mL}$ de emulsão e o tempo de 40 minutos para que esta se estabeleça. Com a adição de $10 \%$ de biodiesel, foi observado um incremento de emulsão no Diesel S10 de $2 \mathrm{~mL}$ e no Diesel S500, um pouco maior, de $3 \mathrm{~mL}$.

Após o ensaio de demulsibilidade, as amostras foram avaliadas na escala Haze [24], para verificação da turbidez. E estes imagens estão ilustradas na Figura 3 (Diesel BX S10) e na Figura 4 (Diesel BX S500).

Foi verificado, na Figura 3, relacionada ao Diesel BX S10 um leve aumento da turbidez, com o aumento do teor de biodiesel no óleo diesel e assim como a formação de emulsão no Diesel B10 S10 este fato está relacionado à higroscopicidade do biodiesel.

Na Figura 4, referente ao Diesel S500, com o aumento do percentual de biodiesel, foi notado uma turbidez acentuada. Principalmente, na amostra de Diesel B10 S500, não é possível visualizar as raias presentes atrás da proveta. Este combustível, o diesel S500, possui uma tendência à incorporação de água maior que o diesel S10. E visando esta quantificação, avaliou-se o teor de água pelo método do Karl Fischer [21]. Estes resultados podem ser visualizados na Tabela 5, estão representados os valores do teor de água das amostras antes do 
ensaio de demulsibilidade, os valores do teor de água da fase óleo após o ensaio de demulsibilidade e a diferença do teor de água incorporado na fase óleo.

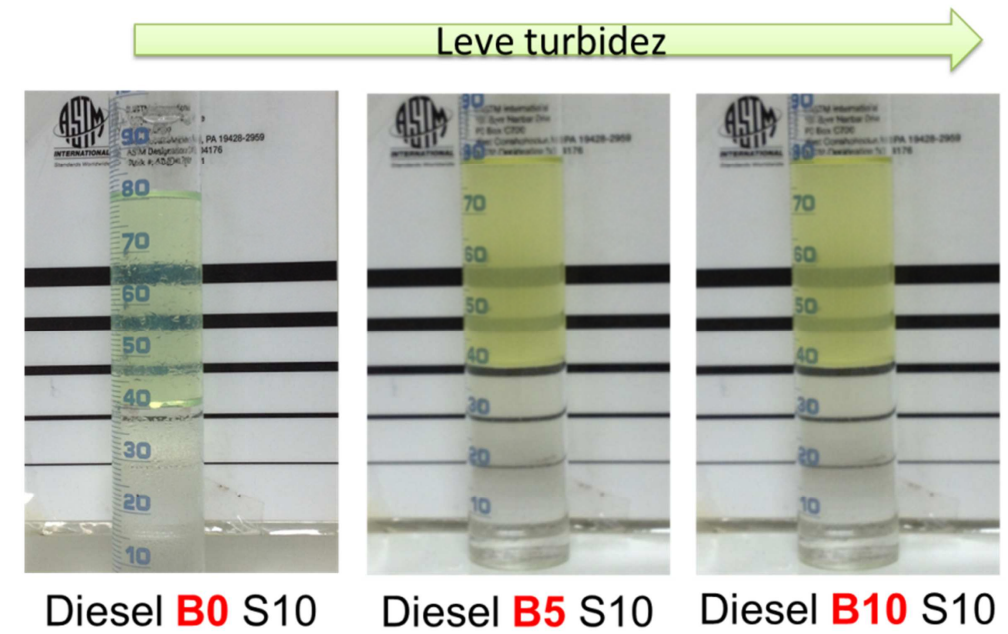

Figura 3 - Análise da turbidez após o ensaio de demulsibilidade nas amostras de Diesel BX S10.

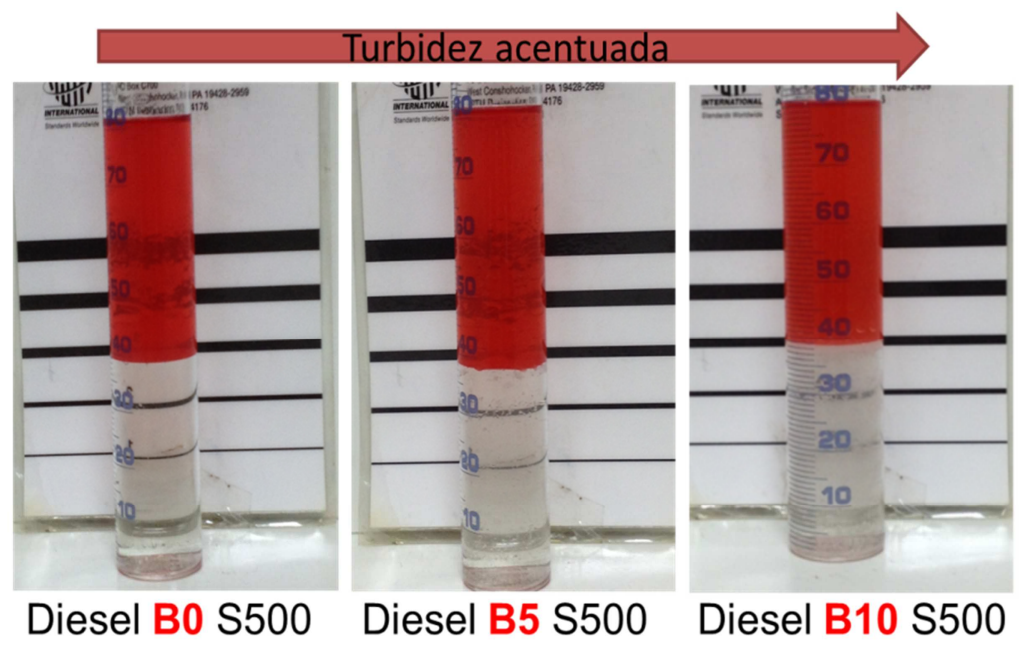

Figura 4 - Análise da turbidez após o ensaio de demulsibilidade nas amostras de Diesel BX S500.

Tabela 5 - Resultados do teor de água (método do Karl Fischer) - Amostras antes do ensaio de demulsibilidade, fase óleo após o ensaio de demulsibilidade e a diferença $(\Delta)$ do teor de água incorporada na fase óleo.

\begin{tabular}{|c|c|c|c|c|c|c|c|c|c|}
\hline \multirow{2}{*}{ Amostras } & \multicolumn{3}{|c|}{ B0 } & \multicolumn{3}{c|}{ B5 } & \multicolumn{3}{c|}{ B10 } \\
\cline { 2 - 10 } & $\mathbf{1}$ & $\mathbf{2}$ & $\mathbf{3}$ & $\mathbf{1}$ & $\mathbf{2}$ & $\mathbf{3}$ & $\mathbf{1}$ & $\mathbf{2}$ & $\mathbf{3}$ \\
\hline Diesel S10 & 83,1 & 150,0 & 66,9 & 56,4 & 430,1 & 373,7 & 87,7 & 565,2 & 477,5 \\
\hline Diesel & 73,5 & 510,0 & 436,5 & 70,8 & 20104,8 & 20034,0 & 100,7 & 22560 & 22459,3 \\
S500 & & & & & & & & & \\
\hline
\end{tabular}

$1=$ Amostras (antes) $\mathrm{mg} / \mathrm{kg} / 2=$ Fase Óleo (após) $\mathrm{mg} / \mathrm{kg} / 3=\Delta$ água mg/kg 
Foram realizados os ensaios dos teores de água antes do ensaio de demulsibilidade e foi verificado que as amostras de Diesel BX S10 e Diesel BX S500 estavam atendendo aos limites especificados na Resolução (ANP 50/2013) [4]. Na amostra de Diesel B0 S10, a incorporação de água, após o ensaio de demulsibilidade foi de $66,9 \mathrm{mg} / \mathrm{kg}$ e na amostra de Diesel B0 S500, este valor foi mais significativo, $436,7 \mathrm{mg} / \mathrm{kg}$. Pode ser visualizado que com o aumento do teor de biodiesel, as amostras de Diesel BX S10 e Diesel BX S500 incorporam uma maior quantidade de água nas fases óleo.

Nas amostras de Diesel B5 S10 e Diesel B5 S500, os valores de água absorvidos são de 373,7 $\mathrm{mg} / \mathrm{kg}$ e 20034,0 mg/kg, respectivamente. E nas amostras com $10 \%$ de biodiesel, os valores de água absorvidos são de 477,5 mg/kg para o Diesel S10 e de 22459, $3 \mathrm{mg} / \mathrm{kg}$ de água para o Diesel S500. Baseado nesses valores e nas Figuras 3 e 4 ,nota-se que diesel S500 possui uma maior afinidade com a água por ser um produto com maior teor de enxofre, mais saturado e menos polar que o Diesel S10 [25].

Em contrapartida, o Diesel S10 possui uma menor tendência à incorporação de água, sofrendo um menor impacto com a adição do biodiesel. E por ter uma maior facilidade de separação da água quando em repouso, requer assim uma maior atenção na drenagem de tanques durante o armazenamento [26].

\section{CONCLUSÃO}

De acordo com os resultados obtidos, observou-se que as amostras de Diesel com maior teor de biodiesel apresentaram um tempo maior para a separação da emulsão. As amostras de Diesel S10 e S500, ambas com 10\% de biodiesel, não separaram por completo, depois do tempo final. Após o ensaio de demulsibilidade, analisou-se o teor de água nas amostras e observou-se que com o aumento do percentual de biodiesel, essa água fica retida na fase óleo, a separação não é efetiva, devido à higroscopicidade do biodiesel. Nas amostras com alto teor de enxofre, Diesel BX S500, nota-se uma maior incorporação da água na fase óleo do que nas amostras com menor teor de enxofre, de Diesel BX S10.

Ao analisar as amostras de B0, B5 e B10 através do ensaio de demulsibilidade verificou-se que foram obtidos resultados coerentes na avaliação do teor de água incorporado à fase óleo. Sendo assim, pode-se dizer que este ensaio se mostrou uma técnica robusta na avaliação dessa propriedade.

Como era esperado, comprovou-se através do ensaio de demulsibilidade que à medida que se aumentou o teor de biodiesel, a mistura de Diesel BX apresentou a presença de formação de emulsões, a dificuldade de separação da água e do óleo, devido à fácil absorção de água do biodiesel.

Além disso, verificou-se que a concentração de enxofre no diesel também é um aspecto importante. Foram comparadas amostras de BX com dois tipos diferentes de diesel: S10 e S500, e verificou-se que as amostras com Diesel BX S500 possuem maior tendência à incorporação de água. Ao passo que as amostras de Diesel BX S10, se separam melhor da água. E tal fato pode ser explicado devido aos processos que ocorrem nas refinarias, o 
combustível com baixo teor de enxofre, é submetido à hidrotratamentos, reduzindo assim compostos polares e sulfurados presentes, o que diminui a sua afinidade com água.

Estas importantes características, ocasionaram controles mais rigorosos, com especificações mais exigentes, que garantem produtos de melhor qualidade.

\section{REFERÊNCIAS}

[1] BRASIL, N. I.; ARAÚJO, M. A. S.; SOUSA, E. C. M. Processamento de petróleo e gás. $1^{\mathrm{a}}$ ed. Rio de Janeiro: LTC, 2012.

[2] CARRETEIRO, R. P.; BELMIRO, P. N. A. Lubrificantes e Lubrificação Industrial. ${ }^{\text {a }}$ ed. Rio de Janeiro: Interciência, 2006.

[3] Confederação Nacional do Transporte - Os impactos da má qualidade do óleo diesel brasileiro - Brasília: CNT, 2012

http://www.cnt.org.br/riomais20/resources/cartilhas/Oleo_Diesel_Final.pdf - Acesso em maio de 2014.

[4] ANP - Agência Nacional do Petróleo, Gás Natural e Biocombustíveis. Resolução no 50 de 23 de dezembro de 2013 - Óleo Diesel. Disponível em: <www.anp.gov.br>. Acesso em novembro de 2014.

[5] ANUÁRIO estatístico brasileiro do petróleo, gás natural e biocombustíveis. ANP. Disponível em: <www.anp.gov.br〉. Acesso em maio de 2014.

[6] Faria, E.A.; Leles, M.I.G.; Ionashiro, M.; Zuppa, T.O.; Antoniosi Filho, N.R. 2002. Estudo da estabilidade térmica de óleos e gorduras vegetais por TG/DTG e DTA. Eclética Química, 27: 10-14.

[7] KNOTHE, G.; GERPEN, J. V.; KRAHL, J.; RAMOS, L.P. Manual do Biodiesel. $1^{\text {a }}$ ed. São Paulo: Edgard Blücher, 2006.

[8] Shahid, E.M., Jamal, Y. 2008. A review of biodiesel as vehicular fuel. Renewable and Sustainable Energy Reviews, 12: 2484-2494.

[9] Srivastava, A., Prasad, R. 2000. Triglycerides-based diesel fuels. Renewable and Sustainable Energy Reviews, 4: 111-133.

[10] OMER, A. M. Energy, Environment and sustainable development. Renewable and Sustainable Energy Reviews. v. 9, p. 265-300, 2008.

[11] Conselho Nacional de Política Energética - CNPE - Resolução $\mathrm{N}^{\circ}$ 2, 13 de março de 2008. Disponível em: <www.mme.gov.br>. Acesso em novembro de 2014.

[12] ANP - Agência Nacional do Petróleo, Gás Natural e Biocombustíveis. Medida Provisória no 647/2014. Disponível em: <www.anp.gov.br>. Acesso em novembro de 2014.

[13] ANP - Agência Nacional do Petróleo, Gás Natural e Biocombustíveis. Resolução no 45 de 25 de agosto de 2014 - Biodiesel. Disponível em: <www.anp.gov.br>. Acesso em novembro de 2014.

[14] KNOTHE, G. Dependence of biodiesel fuel properties on the structure of fatty acid alkyl esters. Fuel Processing Technology, v.85, p. 1059-1070, 2005.

[15] ABNT NBR 15552 - Norma Armazenamento, Transporte, Abastecimento e Controle de Qualidade de Biodiesel e/ou Mistura Óleo Diesel/Biodiesel, ABNT; 2008.

[16] ABNT NBR 14954 - Combustível destilado - Determinação da aparência - 27.02.2011ISBN

[17] ASTM D4052 - 11 - Standard Test Method for Density, Relative Density, and API Gravity of Liquids by Digital Density Meter. DOI: 10.1520/D4052-11 [www.astm.org]. 
[18] ASTM D445 -14e2 - Standard Test Method for Kinematic Viscosity of Transparent and Opaque Liquids (and Calculation of Dynamic Viscosity) DOI: 10.1520/D0445-14E02 [www.astm.org].

[19] ASTM D5453 - 12 - Standard Test Method for Determination of Total Sulfur in Light Hydrocarbons, Spark Ignition Engine Fuel, Diesel Engine Fuel, and Engine Oil by Ultraviolet Fluorescence. DOI: 10.1520/D5453-12 [www.astm.org].

[20] ASTM D93 - 13e1 - Standard Test Methods for Flash Point by Pensky-Martens Closed Cup Tester. DOI: 10.1520/D0093 [www.astm.org].

[21] ASTM D6304 - 07 Standard Test Method for Determination of Water in Petroleum Products, Lubricating Oils, and Additives by Coulometric Karl Fischer Titration. DOI: 10.1520/D6304-07 [www.astm.org].

[22] ABNT NBR 14172 - Óleos derivados de petróleo e fluidos sintéticos - Determinação das características de emulsão - 24.09.2009 - ISBN 978-85-07-01762-2.

[23] ASTM D1401 - 12 - Standard Test Method for Water Separability of Petroleum Oils and SyntheticBFluids. DOI: 10.1520/D1401-12 [www.astm.org].

[24] ASTM Standard D4176-04 (2009). Standard test method for free water and particulate contamination in distillate fuels (visual inspection procedures). West Conshohocken, PA: ASTM International; 2009. Doi: 10.1520/D4176- 04R09 [www.astm.org].

[25] BALSTER, L. M., ZABARNICK, S., STRIEBICH, R. C., et al. Analysis of Polar Species in Jet Fuel and Determination of Their Role in Autoxidative Deposit Formation, Energy \& Fuels, v. 20, n. 6, pp. 2564 -2571, 2006.

[26] LORA, E. E. S.; VENTURINI, O. J. Biocombustíveis. $1^{\text {a }}$ ed. Rio de Janeiro: Interciência, 2012. 